\title{
When Personality Is the Problem: Managing Patients With Difficult Personalities on the Acute Care Unit
}

\author{
Megan Riddle, MD, PhD ${ }^{1 \star}$, Timothy Meeks, MN, RN-BC², Carrol Alvarez, MS, RN, CS², Amelia Dubovsky, MD ${ }^{1,2,3}$
}

\begin{abstract}
${ }^{1}$ Psychiatry Residency Program, Department of Psychiatry and Behavioral Sciences, University of Washington, Seattle, Washington; ${ }^{2}$ Department of Clinical Education, Harborview Medical Center, Seattle, Washington; ${ }^{3}$ Department of Psychiatry and Behavioral Sciences, University of Washington and Harborview Medical Center, Seattle, Washington.
\end{abstract}

Personality disorders are pervasive patterns of maladaptive behaviors, thoughts, and emotions that often go unrecognized and can wreak havoc in the patient's interpersonal life. These inflexible patterns of managing the world can be disruptive when an individual is admitted to the hospital, causing distress for both the patient who lacks the skills to deal with the expectations of the hospital environment and the treatment team who can feel ill equipped to manage such behavior. Having a personality disorder has implications for an individual's healthcare outcomes; those with a personality disorder have a life expectancy nearly 2 decades shorter than the general population for a multitude of reasons, among them trouble interacting with the healthcare system. Although a diagnosis of a specific personality disorder may be difficult to make on an acute care unit, identification of dysfunctional personality structures can provide opportunity for better management of an individual patient's medical and psychological needs. This review focuses on the identification of these individuals in the acute care setting and provides an overview of evidence-based behavioral and pharmacological interventions. Journal of Hospital Medicine 2016;11:873-878. (C) 2016 Society of Hospital Medicine
Much has been written about the importance of the doctor-patient relationship, with a positive therapeutic alliance being associated with both improvement in patient healthcare outcomes and physician job satisfaction. ${ }^{1,2}$ However, some patients severely test their physician's ability to provide needed care. These patients can rankle even experienced clinicians, leaving them feeling frustrated and ineffectual while consuming disproportionate amounts of clinical time. Although these disruptive acts may feel volitional and purposeful to the clinicians attempting to provide care, they may stem from a dysfunctional personality structure. Personality disorders are pervasive patterns of maladaptive behaviors, thoughts, and emotions that often go unrecognized and can wreak havoc in the patient's interpersonal life. ${ }^{3}$ These inflexible patterns of managing the world can be disruptive when an individual is admitted to the hospital, causing distress for both the patient who lacks the skills to deal with the expectations of the hospital environment and the treatment team who can feel ill equipped to manage such behaviors. ${ }^{4,5}$ Here, we discuss personality disorders, how they can manifest in the hospital setting, and interventions to assist both the individual and the team.

\footnotetext{
*Address for correspondence and reprint requests: Megan Riddle, MD, Psychiatry and Behavioral Sciences, University of Washington School of Medicine, Box 356560, 1959 NE Pacific Street, Seattle, WA 98195-65601; Telephone: 360-303-9113; Fax: 206-685-8952; E-mail: riddlem2@uw.edu

Additional Supporting Information may be found in the online version of this article.

Received: April 25, 2016; Revised: July 7, 2016; Accepted: July 18, 2016

2016 Society of Hospital Medicine DOI 10.1002/jhm.2643

Published online in Wiley Online Library (Wileyonlinelibrary.com).
}

Although personality disorders come in a variety of forms, central to all is interpersonal disarray with difficulty forming and maintaining acceptable relationships with others. In the hospital setting, the patient needs to be able to relate to, and cooperate with, a myriad of different care providers all while under some degree of physical and emotional distress. This can be destabilizing even for those without personality issues. For those with personality disorders, it is nearly inevitable that conflict will arise. Although true prevalence rates can be difficult to ascertain due to diagnostic challenges, surveys have found $4 \%$ to $15 \%$ of the population are affected by at least 1 personality disorder. ${ }^{6}$ The prevalence is thought to be even higher among those seeking healthcare services, with researchers suggesting that 1 in 4 primary care patients meet criteria for a personality disorder. ${ }^{6,7}$

Having a personality disorder has implications for an individual's healthcare outcomes. Studies in the United Kingdom have shown that those with a personality disorder have a life expectancy nearly 2 decades shorter than the general population. ${ }^{8}$ Although suicide and homicide account for part of this, they also have increased risk of a number of health issues, including obesity, metabolic syndrome, cardiovascular disease, and sleep disorders. ${ }^{9}$ In addition to lifestyle factors such as drinking and drug use, it has been suggested that dysfunctional personality structures may interfere with the ability to access and utilize care, leading to higher morbidity and mortality. ${ }^{7}$

In addition to impacting their own life, individuals with personality disorders have a tendency to disrupt the environment around them. They often elicit strong emotional responses from others that can range from a desire to help and protect to frustration and a sense 
TABLE 1. Personality Disorders and Their Manifestations in the Acute Care Setting

\begin{tabular}{lll}
\hline Personality Disorders & \multicolumn{1}{c}{ Features } & Possible Manifestations in the Hospital \\
\hline Cluster A & Odd and eccentric, socially avoidant & - Mistrust of medical staff and treatments offered \\
Paranoid & Highly suspicious of others; interpret malice where none was intended & - Hostility toward treatment team \\
Schizoid & Minimal social relationships; limited emotional range & - Accusations of exploitation and harm without reasonable evidence \\
Schizotypal & Eccentric behavior and magical thinking; uncomfortable with close relationships & - General sense from the team that something is "off" \\
Cluster B & Emotionally labile and impulsive & - Spliting of the team, clear favorite providers and hated providers \\
Antisocial & Frequent disregard for rights of others & - Extremes of emotion with responses out of proportion to the situation \\
Borderline & Impulsive with volatile interpersonal relationships & - Rapid escalation when they perceive their needs not being met \\
Histrionic & Disproportionate emotionality with engagement seeking & - Evoke a strong emotional response from the team, taking up time out of \\
Narcissistic & Grandiose, seeks admiration & proportion to their medical illness \\
& & - Help-rejecting behavior \\
& & - Fear of abandonment manifesting as escalation of behavior around \\
Cluster C & discharge \\
Avoidant & - Resistance to participating in their own care \\
Dependent & Anxious and neurotic & - Frequent demands on the staff \\
Obsessive-compulsive & Socially fearful with feelings of inadequacy & - Particular, sometimes seemingly illogical, preferences regarding their \\
& Need to be taken care of, often manifesting as clinging and obsequious behavior & care or other aspects of their stay
\end{tabular}

of loathing. ${ }^{10}$ The presence of a personality disorder often comes to light in the hospital when the patient is feeling vulnerable and acts out, evoking strong responses from team members. In the literature, patients with personality disorders are frequently referred to as a "difficult" or even "hateful." 11 These individuals can be emotionally draining to care for, and the team must manage their own divergent responses in addition to the patient's disruptive behavior. Understanding personality disorders as a mental illness and using behavioral interventions can help to ease these interactions.

\section{PERSONALITY DISORDERS: AN OVERVIEW}

Personality disorders are characterized by persistent patterns of emotional reactivity, interpersonal interactions, and ways of perceiving the world that are inflexible and maladaptive and lead to significant distress and dysfunction. ${ }^{3,7}$ These disorders are notable for the interactive nature of the diagnosis; rather than being completely dependent on the individual's symptoms, a significant component of identification depends on how these individuals relate to others. ${ }^{7}$ Although the trajectory can change over time, personality disorders are generally pervasive across the lifetime of an individual, beginning in adolescence or early adulthood. ${ }^{7,12}$ Personality disorders are divided into 3 clusters (Table 1).

\section{Cluster A}

Those falling into cluster A, which includes paranoid, schizoid, and schizotypal personality disorders, are odd and eccentric and often avoid social engagement ${ }^{3}$; these individuals have few friends or associates and do not care to make more. At times, their unusual thinking can be difficult to differentiate from primary psychotic disorders like schizophrenia.

\section{Cluster B}

Cluster B is most heavily studied, consisting of antisocial, borderline, histrionic, and narcissistic personality disorders. These individuals share a high degree of emotional lability and erratic behavior. ${ }^{3}$ Frequently, their tendency toward impulsive and self-destructive behaviors can result in the need for medical care.

\section{Cluster C}

Cluster C includes avoidant, dependent, and obsessive-compulsive personality disorders. These individuals are often anxious and fearful. Like individuals in Cluster A, they have few friends; unlike Cluster A, they long for friendships but struggle to make them. On the inpatient unit, these individuals may have trouble engaging in needed care, relying heavily on others to have their needs met or may be very particular about how their care is administered.

\section{NEUROPHYSIOLOGY}

Personality disorders are the product of complex interactions between genes and environment. These disorders are highly heritable, with $55 \%$ to $72 \%$ heritability across the 3 clusters. ${ }^{13-15}$ Studies have implicated alterations in the serotonin system as playing a role in the underlying pathophysiology, which may contribute to the emotional dysregulation. ${ }^{16-18}$ Neuroimaging has shown alterations in regions of the brain related to emotional reactivity and the processing of social interactions, suggesting neural mechanisms behind these individuals' difficulty with interpersonal relationships. ${ }^{19-22}$

\section{IDENTIFICATION OF PERSONALITY DISORDERS}

These disorders are under-recognized due, at least in part, to difficulty in making the diagnosis. ${ }^{7}$ With 10 different personality disorders, many with overlapping characteristics, establishing a specific diagnosis can be time consuming, and a single individual may fit multiple different personality disorders. ${ }^{7}$ Although selfreport surveys and structured interviews exist, these are often time consuming or inaccurate. ${ }^{7}$ It is unlikely to be practical to make a diagnosis of a specific 
TABLE 2. Behavioral Interventions

Clinical Examples and Behavioral Interventions

\begin{tabular}{|c|c|c|}
\hline Background & Situation & Response \\
\hline $\begin{array}{l}\text { Cluster A: Mr. A is a 75-year-old man transferred from his small } \\
\text { town after a myocardial infarction. Although he has improved } \\
\text { medically, he repeatedly expresses distrust and dissatisfaction } \\
\text { with his doctors. He refuses to go to a skilled nursing facility } \\
\text { but will not work with physical therapy to discharge home. He } \\
\text { lives alone and has worked as a cattle rancher all his life. }\end{array}$ & $\begin{array}{l}\text { Mr. A repeatedly accuses his } \\
\text { team of being "in this for } \\
\text { the money." At times he } \\
\text { mutters about govern- } \\
\text { ment conspiracies. }\end{array}$ & $\begin{array}{l}\text { Check the team's emotions and reinforce desired behaviors and move past negative ones: } \\
\text { - Recognize paranoia as part of the illness. } \\
\text { - Rather than confront the paranoia, ignore this behavior as long as it is not directly interfering with care. }\end{array}$ \\
\hline $\begin{array}{l}\text { Cluster B: Ms. B is a 22-year-old woman admitted after a car acci- } \\
\text { dent resulting in multiple fractures. The pain service is con- } \\
\text { sulted due to her ever-increasing need for opiates. When the } \\
\text { team first meets her, she is bright, effusing, "Thank you for } \\
\text { coming! My other doctors have no idea how to control my } \\
\text { pain." She starts crying, "I Just can't do this anymore." Midway } \\
\text { through the conversation, she offers, "I can tell you are the } \\
\text { best doctors I've had. Finally, I have someone who under- } \\
\text { stands." Later, the pain team receives numerous pages that } \\
\text { the patient is demanding to see them. The following day she is } \\
\text { furious at the team for not "keeping your promises." Nursing } \\
\text { complains about her unwillingness to cooperate with dressing } \\
\text { changes, insisting she only work with certain people, "Because } \\
\text { they understand me." }\end{array}$ & $\begin{array}{l}\text { Ms. B is crying inconsolably, } \\
\text { saying, "I just can't stand } \\
\text { being in the hospital } \\
\text { anymore. They won't give } \\
\text { me the pain meds I } \\
\text { need." }\end{array}$ & $\begin{array}{l}\text { Reinforce desired behaviors and move past negative ones: } \\
\text { - Interact in a neutral manner to avoid reinforcing the disruptive behavior. } \\
\text { - If she becomes threatening or insulting, label the behavior and give her } 1 \text { opportunity to stop. "Cursing } \\
\text { upsets me. It's hard for me to help someone when they're cursing at me." This wording separates the } \\
\text { behavior from the person. } \\
\text { - If she is able to calm herself, thank her (to reinforce this behavior) and offer to help. } \\
\text { - If she continues to escalate, you can say, "You seem to be upset. I'll come back when it is a better } \\
\text { time." Withdrawal of social contact can be a powerful tool. Return after a brief period to see if she has } \\
\text { been able to calm down and, if so, re-engage. Re-engagement is key to reinforce calm, socially } \\
\text { acceptable behavior. } \\
\text { Check the team's emotions: } \\
\text { - Recognize patients with challenging behaviors can place a strong emotional toll on the team, particularly } \\
\text { nursing staff who must frequently interact with these patients. } \\
\text { - Offer support to all members of the team to ensure appropriate patient care. } \\
\text { Offer validation and reinforce desired behaviors and move past negative ones: } \\
\text { - Offer empathy but then move to skill building. "I can see you are upset. Is there anything that helps you } \\
\text { when you are feeling this way?" } \\
\text { - If the patient is unable to come up with anything feasible, offer her choices, such as walking with her } \\
\text { around the unit or listening to music. }\end{array}$ \\
\hline $\begin{array}{l}\text { Cluster C: Mr. C is a 57-year-old man admitted for hyperosmolar } \\
\text { hyperglycemic state. His condition has now stabilized, but } \\
\text { when the nutritionist attempts to meet with him, he says he } \\
\text { has a migraine. Later, when the diabetes nurse comes to dis- } \\
\text { cuss his insulin regimen, he is "too tired to learn anything." } \\
\text { When she persists, he listens, but repeatedly says, "l'm never } \\
\text { going to be able to do this" and is unwilling to participate fur- } \\
\text { ther. He repeatedly uses his call button, asking for help to the } \\
\text { bathroom, despite being ambulatory previously. He talks for } \\
\text { extended periods with nursing staff, sharing his fears about his } \\
\text { inability to care for himself and his concerns that this will hap- } \\
\text { pen again. }\end{array}$ & $\begin{array}{l}\text { Mr. C is repeatedly pressing } \\
\text { his nurse call button } \\
\text { multiple times throughout } \\
\text { the day for seemingly } \\
\text { trivial requests. }\end{array}$ & $\begin{array}{l}\text { Establish parameters: } \\
\text { - Mr. C is seeking contact with others. Have nursing arrange a regular schedule for checking in on the } \\
\text { patient, such as every hour between } 10 \text { to and } 10 \text { after the hour. These visits can be kept brief, but offer } \\
\text { a structure for the patient and encourage him or her to bundle their requests. } \\
\text { - Caregivers may also consider having Mr. C sit by the nurse's station to increase social interaction. } \\
\text { Keep the message consistent: } \\
\text { - Work to maintain increased social contact across nursing shifts. }\end{array}$ \\
\hline
\end{tabular}

personality disorder while in the hospital. Instead, the focus should be placed on identifying impaired personality structures that interfere with interpersonal relationships and thereby disrupt the course of treatment. Consider a personality disorder if any of the following features are present:

- The patient elicits a strong emotional reaction from providers; these may vary markedly between providers.

- The patient's emotional responses may appear disproportionate to the inciting event.

- The patient is on a number of different psychiatric medications with little relief of symptoms.

- The patient takes up a disproportionate amount of the providers' time.

- The patient externalizes blame, seeing others as the source of discomfort or distress and therefore sees others as the solution.
Once identified, steps can be taken to help both the team and the patient.

\section{BEHAVIORAL INTERVENTIONS}

The first line of intervention for individuals with dysfunctional personality structures is behavioral, changing the way the team and patient interact (Table 2). Such interventions have long been the cornerstone of treatment for these individuals. ${ }^{23}$ The preponderance of the research has focused on cluster $\mathrm{B}$, and specifically individuals with borderline personality disorder, and applying these principles more broadly is largely based on expert opinion.

\section{Check the Team's Emotions}

Managing patients with personality disorders begins by recognizing that these individuals evoke strong responses from even the most seasoned professional. ${ }^{10,11,24,25}$ Reactions toward people with personality 
disorders can range from a need to care for and protect the patient to feelings of futility or contempt. ${ }^{10}$ Referred to as "countertransference," these unconscious emotional reactions are common, but can interfere with medical care. ${ }^{26}$ Given the increased understanding of the importance of team cohesion in patient care, ${ }^{27}$ part of treating an individual with a personality disorder involves recognizing and managing the responses elicited amongst all members of the team. The disparate feelings among team members, which may be driven by different patient behaviors with different people, can lead to a variety of responses including overinvolvement, withdrawal, or even aggression. ${ }^{28}$ Recognizing and discussing these differing reactions can help maintain team cohesion and support appropriate patient care.

\section{Offer Empathy and Validation}

Patients with personality disorders were often raised in invalidating environments and their ongoing intense emotional reactions can lead to perpetuation of invalidating responses from their caregivers. ${ }^{29}$ They are accustomed to eliciting a defensive response from others and can be deliberately provocative, as these intense emotional interactions are comfortable territory, keeping providers feeling off balance and under attack. Instead, offering an empathic response can deescalate situations and is associated with the lowest level of invoked anger in patients. ${ }^{30}$ Empathy can take the form of validation by acknowledging a person's feelings, thoughts, and emotions as legitimate, even if others may not fully understand or agree with them. As extreme as a patient's response may seem, he or she is genuinely experiencing these feelings and beliefs. Validation includes listening nonjudgmentally, objectively naming emotions the patient is experiencing, and conveying that the patient's response makes sense within the context of the situation. ${ }^{31}$ This can include acknowledging the patient's level of distress, saying things such as, "I can see you are really frustrated" or "I am concerned that what I just said has been upsetting." Empathy is more than words; it is the ability to see a situation from someone else's point of view. An empathic approach acknowledges the patient's intense emotional response to the challenges of hospitalization without frustration and judgment. Maintaining an empathic-or even simply neutralstance can avoid a power struggle and also improves the therapeutic alliance with the patient. ${ }^{32}$

\section{Establish Parameters but Pick the Battles}

Individuals with personality disorders have trouble perceiving social boundaries. Even trained mental health professionals find this difficult to navigate. ${ }^{33}$ The provider's first response is often to establish rigid boundaries. However, rigid rules can lead to power struggles between patients and providers, with limits being perceived as punitive. Instead of a list of rules, the creation of boundaries requires a thoughtful, practical establishment of parameters for both the individual and staff. ${ }^{34}$ This may include guidelines for frequent, predictable nursing checks on the patient so that attention is provided on a time-contingent rather than behavior-contingent basis. If the patient remains dysregulated after a brief attempt to problem solve a nonemergent issue, staff can walk away with the comment that they will return within a specified period of time when things are calmer. If the patient is able to engage in the problem-solving process, this has the advantage of generating a plan both can agree with while supporting more effective skills in the patient. Rather than a list of stringent rules, consider what is truly necessary for patient safety and well-being.

\section{Keep the Message Consistent}

Hospital care involves many moving parts; nursing staff, the primary team, support staff, and consultants all interact with the patient throughout the day, sometimes providing conflicting messages. Although the typical patient can tolerate this, those with personality disorders have trouble dealing with the inconsistency, and this can exacerbate other problems. Carefully consider potentially contentious issues, such dosing of pain medications and benzodiazepines, and ensure that the team offers a consistent plan. ${ }^{34}$ Ideally, meet with the patient as a team, including nursing, to convey a unified message.

\section{Reinforce Desired Behaviors and Move Past Maladaptive Ones}

Often in the life of a person with a personality disorder, their interpersonal interactions are negative. These patients are accustomed to negotiating a chaotic world. When not acting out, the patient may receive less attention while nursing and physician attention is appropriately distributed to other patients. Inadvertently, this reinforces using provocative behavior to get attention. Instead, if the patient is not demanding attention, providers should take the opportunity to provide positive reinforcement for calm behavior. This can be done by establishing a routine menu of interactions with the patient that occur when they are not acting in a disruptive manner; this avoids engagement being contingent on negative behaviors. ${ }^{4}$ For example, having a non-illness-related conversation during a dressing change or offering the patient a snack after a positive (or neutral) interaction can reinforce desirable behaviors. In contrast, when patients exhibit disruptive or inappropriate behaviors, the caregiver should respond by removing what the patient seeks, usually engagement, with a neutral attitude to avoid reinforcing the behavior: "You seem upset. I'll come back when you feel better." By not reinforcing maladaptive behaviors, caregivers can decrease or extinguish such behaviors over time. ${ }^{29}$ If the situation is nonemergent, the caregiver should briefly acknowledge the patient's 
TABLE 3. When to Consider a Psychiatric Consult

Safety assessment in a patient who has threatened or engaged in self-harming behavior or harm to others

Diagnostic clarification, particularly when there is concern for a co-occurring psychiatric illness

Creation of a more complex behavioral plan

Facilitation of interdisciplinary discussion and problem-solving around patients with challenging behaviors

Assistance with establishment of outpatient psychiatric care when appropriate

distress and then focus on possible solutions: "I can see you are really upset right now. What helps you in these situations?" This both validates the patient's emotional state and encourages him or her to engage in problem solving around his or her distress. ${ }^{29}$ If the patient is unable to identify a coping strategy in the moment, suggesting possibilities, such as walking around the unit or listening to music, can help the patient move past their intense emotions while also encouraging skill building.

\section{PHARMACOLOGICAL INTERVENTIONS}

Although there are no Food and Drug Administration-approved medications for treatment of personality disorders, there is limited evidence for use of pharmacological interventions to address particular features of these disorders, such as impulsivity, affective dysregulation, or cognitive-perceptual symptoms. ${ }^{35}$ Antipsychotics can be helpful in treating cognitive disturbances such as paranoia and dissociation that some of these patients experience. ${ }^{35}$ Antidepressants may have a relatively small effect on anxiety and anger. ${ }^{35}$ Mood stabilizers are shown to have a positive impact on impulsivity, anger, anxiety, and depressed mood. ${ }^{35}$ However, medication should be used with caution, as polypharmacy is a significant problem with these patients and may have limited utility. Up to $40 \%$ of patients with borderline personality disorder take 3 or more psychotropic medications, many of which can have significant side effects, ${ }^{36}$ and 1 in 3 are prescribed benzodiazepines despite a lack of evidence and potential for abuse. ${ }^{37}$ Thus, although medications may offer an opportunity to target specific symptoms, the focus of management for patients with personality disorders should be behavioral rather than pharmacological.

\section{CONSIDER A CONSULT}

Patients with personality disorders can be very difficult to treat, and it may be necessary to consult psychiatry. There are a number of situations in which a formal psychiatric consultation is indicated (Table 3). Patients with personality disorders, particularly cluster $\mathrm{B}$, may present for treatment after harming themselves or others. ${ }^{38}$ A psychiatric consultation can provide a formal risk assessment, help with behavior and medication management while the patient is hospitalized, and determine whether follow-up psychiatric care is appropriate. $^{39}$ The psychiatry team can also offer a more complete diagnostic formulation, including screening for disorders that often co-occur with personality disorders, such as depression and anxiety, and recommend treatment options. ${ }^{39}$ In addition, if initial attempts at behavioral interventions are ineffectual, a psychiatric consult may be able to provide additional guidance in behavioral modifications. ${ }^{40}$ This is especially appropriate if the patient's behaviors are interfering with medical care. A psychiatric consult can also provide additional support around issues of countertransference that can arise when managing patients with dysfunctional personality structures. ${ }^{41,42}$

As with all interventions, the psychiatric consult is not without its side effects. Regardless of personality structure, it is not uncommon for patients to be initially opposed to engaging with psychiatry. ${ }^{43}$ Individuals with personality disorders can be particularly susceptible to a rupture of the therapeutic alliance, ${ }^{44}$ and calling a psychiatric consult can affect the therapeutic relationship with the primary team, as the patient may feel that others are judging them and can also be part of a greater theme of help rejecting. ${ }^{11}$ However, this rupture may be repaired as the patient comes to see the psychiatry team as an ally. Even for patients who refuse to engage with the consult-liaison team, there may be a benefit to a consult, as the consultants can offer strategies to the primary team and help establish a plan of care to facilitate ongoing treatment of the patient's medical needs without direct contact with the patient. These situations illustrate that a psychiatric consult cannot be done in isolation and requires collaboration with the primary team, nurses, and other support staff for interventions to be effective.

\section{CONCLUSIONS}

In his now famous speech Dr. Francis W. Peabody gave to Harvard Medical School he noted that "[T]he secret of the care of the patient is caring for the patient." 45 Patients with a dysfunctional personality structure can make this task difficult. They can appear to reject the very help we have to offer, divide the team, absorb great amounts of time, and evoke strong feelings of frustration and resentment. However, by understanding that the way in which they interact with the world is in part the product of biology and upbringing, we can better recognize how ill these individuals can be. Just as a patient with diabetes requires management of his blood glucose when admitted for pneumonia, those with personality disorders require management of their mental illness while their other medical conditions are addressed.

Although personality disorders can seem intractable, studies have shown that, like many chronic illnesses, the severity can wax and wane over time with remissions and relapses. Notably, rates of remission for borderline personality disorder at 10 years are comparable to those for major depressive disorder, bipolar disorder, and panic disorder, with lower rates of 
relapse even without specific treatment, suggesting they are not entirely intractable. ${ }^{46}$ However, the stress of hospitalization can easily exacerbate the symptoms of a personality disorder. By providing an empathic approach that addresses the emotional responses of the team while also reinforcing positive behaviors of the patient, the hospital stay can be an opportunity for these individuals to get needed support and develop new skills while also having their physical needs addressed.

Disclosures: Nothing to report.

\section{References}

1. Lee YY, Lin JL. The effects of trust in physician on self-efficacy, adherence and diabetes outcomes. Soc Sci Med. 2009;68(6):1060-1068.

2. Fuertes JN, Mislowack A, Bennett J, et al. The physician-patient working alliance. Patient Educ Couns. 2007;66(1):29-36.

3. Diagnostic and Statistical Manual of Mental Disorders, Fifth Edition. Arlington, VA: American Psychiatric Association; 2013.

4. Runyon N, Allen CL, Ilnicki SH. The borderline patient on the medsurg unit. Am J Nursing. 1988;88(12):1644-1650.

5. Kealy D, Steinberg PI, Ogrodniczuk JS. "Difficult" patient? Or does he have a personality disorder? J Fam Pract. 2014;63(12):697-703.

6. Grant BF, Hasin DS, Stinson FS, et al. Prevalence, correlates, and disability of personality disorders in the United States: results from the national epidemiologic survey on alcohol and related conditions. J Clin Psychiatry. 2004;65(7):948-958.

7. Tyrer P, Reed GM, Crawford MJ. Classification, assessment, prevalence, and effect of personality disorder. Lancet. 2015;385(9969): 717-726.

8. Fok ML, Hayes RD, Chang CK, Stewart R, Callard FJ, Moran P. Life expectancy at birth and all-cause mortality among people with personality disorder. J Psychosom Res. 2012;73(2):104-107.

9. Dixon-Gordon KL, Whalen DJ, Layden BK, Chapman AL. A systematic review of personality disorders and health outcomes. Can Psychol. 2015;56(2):168-190.

10. Colli A, Tanzilli A, Dimaggio G, Lingiardi V. Patient personality and therapist response: an empirical investigation. Am J Psychiatry. 2014; 171(1):102-108.

11. Groves JE. Taking care of the hateful patient. N Engl J Med. 1978; 298(16):883-887.

12. Newton-Howes G, Clark LA, Chanen A. Personality disorder across the life course. Lancet. 2015;385(9969):727-734

13. Kendler KS, Myers J, Torgersen S, Neale MC, Reichborn-Kjennerud T. The heritability of cluster A personality disorders assessed by both personal interview and questionnaire. Psychol Med. 2007;37(5):655665.

14. Gjerde LC, Czajkowski N, Roysamb E, et al. The heritability of avoidant and dependent personality disorder assessed by personal interview and questionnaire. Acta Psychiatr Scand. 2012;126(6):448-457.

15. Torgersen S, Myers J, Reichborn-Kjennerud T, Roysamb E, Kubarych TS, Kendler KS. The heritability of Cluster B personality disorders assessed both by personal interview and questionnaire. J Pers Disord. 2012;26(6):848-866.

16. Bukh JD, Bock C, Kessing LV. Association between genetic polymorphisms in the serotonergic system and comorbid personality disorders among patients with first-episode depression. J Pers Disord. 2014; 28(3):365-378

17. Perez-Rodriguez MM, Weinstein S, New AS, et al. Tryptophanhydroxylase 2 haplotype association with borderline personality disorder and aggression in a sample of patients with personality disorders and healthy controls. J Psychiatr Res. 2010;44(15):1075-1081.

18. Checknita D, Maussion G, Labonte B, et al. Monoamine oxidase A gene promoter methylation and transcriptional downregulation in an offender population with antisocial personality disorder. Br J Psychiatry. 2015;206(3):216-222.

19. Boen E, Westlye LT, Elvsashagen T, et al. Regional cortical thinning may be a biological marker for borderline personality disorder. Acta Psychiatr Scand. 2014;130(3):193-204.

20. Thoma P, Friedmann C, Suchan B. Empathy and social problem solving in alcohol dependence, mood disorders and selected personality disorders. Neurosci Biobehav Rev. 2013;37(3):448-470.
21. Liu H, Liao J, Jiang W, Wang W. Changes in low-frequency fluctuations in patients with antisocial personality disorder revealed by resting-state functional MRI. PLoS One. 2014;9(3):e89790.

22. Yang Y, Raine A. Prefrontal structural and functional brain imaging findings in antisocial, violent, and psychopathic individuals: a metaanalysis. Psychiatry Res. 2009;174(2):81-88.

23. Bateman AW, Gunderson J, Mulder R. Treatment of personality disorder. Lancet. 2015;385(9969):735-743.

24. Groves JE. Management of the borderline patient on a medical or surgical ward: the psychiatric consultant's role. Int J Psychiatry Med. 1975;6(3):337-348.

25. Bodner E, Cohen-Fridel S, Mashiah M, et al. The attitudes of psychiatric hospital staff toward hospitalization and treatment of patients with borderline personality disorder. BMC Psychiatry. 2015;15:2.

26. Park DB, Berkwitt AK, Tuuri RE, Russell WS. The hateful physician: the role of affect bias in the care of the psychiatric patient in the ED. Am J Emerg Med. 2014;32(5):483-485.

27. McAllister C, Leykum LK, Lanham H, et al. Relationships within inpatient physician housestaff teams and their association with hospitalized patient outcomes. J Hosp Med. 2014;9(12):764-771.

28. O'Kelly G. Countertransference in the nurse-patient relationship: a review of the literature. J Adv Nurs. 1998;28(2):391-397.

29. Lynch TR, Chapman AL, Rosenthal MZ, Kuo JR, Linehan MM. Mechanisms of change in dialectical behavior therapy: theoretical and empirical observations. J Clin Psychol. 2006;62(4):459-480.

30. Lancee WJ, Gallop R, McCay E, Toner B. The relationship between nurses' limit-setting styles and anger in psychiatric inpatients. Psychiatr Serv. 1995;46(6):609-613.

31. Prunetti E, Framba R, Barone L, Fiore D, Sera F, Liotti G. Attachment disorganization and borderline patients' metacognitive responses to therapists' expressed understanding of their states of mind: a pilot study. Psychother Res. 2008;18(1):28-36.

32. Caligor E, Levy KN, Yeomans FE. Narcissistic personality disorder: diagnostic and clinical challenges. Am J Psychiatry. 2015;172(5):415422 .

33. Eren N, Sahin S. An evaluation of the difficulties and attitudes mental health professionals experience with people with personality disorders. J Psychiatr Ment Health Nurs. 2016;23(1):22-36.

34. Trimpey M, Davidson S. Nursing care of personality disorders in the medical surgery setting. Nurs Clin North Am. 1998;33(1):173-186.

35. Ingenhoven T, Lafay P, Rinne T, Passchier J, Duivenvoorden H. Effectiveness of pharmacotherapy for severe personality disorders: metaanalyses of randomized controlled trials. J Clin Psychiatry. 2010; 71(1):14-25.

36. Zanarini MC, Frankenburg FR, Hennen J, Silk KR. Mental health service utilization by borderline personality disorder patients and Axis II comparison subjects followed prospectively for 6 years. J Clin Psychiatry. 2004;65(1):28-36.

37. Paton C, Crawford MJ, Bhatti SF, Patel MX, Barnes TR. The use of psychotropic medication in patients with emotionally unstable personality disorder under the care of UK mental health services. J Clin Psychiatry. 2015;76(4):e512-e518.

38. Mergui J, Raveh D, Gropp C, Golmard JL, Jaworowski S. Prevalence and characteristics of cluster B personality disorder in a consultationliaison psychiatry practice. Int J Psychiatry Clin Pract. 2015;19(1): $65-70$.

39. Bronheim HE, Fulop G, Kunkel EJ, et al. The Academy of Psychosomatic Medicine practice guidelines for psychiatric consultation in the general medical setting. The Academy of Psychosomatic Medicine. Psychosomatics. 1998;39(4):S8-S30.

40. Huyse FJ, Strain JJ, Hammer JS. Interventions in consultation/liaison psychiatry. Part I: Patterns of recommendations. Gen Hosp Psychiatry. 1990;12(4):213-220.

41. Nash SS, Kent LK, Muskin PR. Psychodynamics in medically ill patients. Harv Rev Psychiatry. 2009;17(6):389-397.

42. Zarr ML. Patient dynamics, staff burnout, and consultation-liaison psychiatry. Physician Exec. 1991;17(5):37-40.

43. Bursztajn H, Barsky AJ. Facilitating patient acceptance of a psychiatric referral. Arch Intern Med. 1985;145(1):73-75.

44. Bender DS. The therapeutic alliance in the treatment of personality disorders. J Psychiatr Pract. 2005;11(2):73-87.

45. Hurst JW. Dr. Francis w. Peabody, we need you. Tex Heart Inst J. 2011;38(4):327-328; discussion 328-329.

46. Gunderson JG, Stout RL, McGlashan TH, et al. Ten-year course of borderline personality disorder: psychopathology and function from the Collaborative Longitudinal Personality Disorders study. Arch Gen Psychiatry. 2011;68(8):827-837. 